\title{
High-performance airfoil with low reynolds-number dependence on aerodynamic characteristics
}

\begin{abstract}
In the low-Reynolds-number range below $R e=60,000, \mathrm{SD} 7003$ and Ishii airfoils are known as high-performance low-Reynolds-number airfoils with a relatively high lift-to-drag ratios. Although the aerodynamic characteristics at particular Reynolds numbers have been thoroughly studied, research is lacking on how Reynolds numbers affect the aerodynamic characteristics that become pronounced for general low-Reynolds-number airfoils. This study investigates the Reynolds number dependence on the aerodynamic performance of these two airfoils. The results demonstrate that the Ishii airfoil is particularly less dependent on the Reynolds number of the lift curve compared to the SD7003 airfoil. Although there is a slight difference in the high angles of attack above the maximum lift coefficient, the lift slope hardly changes, even when the Reynolds number varies.
\end{abstract}

Keywords: low-reynolds-number, aerodynamics, reynolds number dependence, separation bubble, ishii airfoil
Volume 3 Issue 2 - 2019

\author{
Masayuki Anyoji, Daiki Hamada \\ Interdisciplinary Graduate School of Engineering Sciences, \\ Kyushu University, Japan
}

\begin{abstract}
Correspondence: Masayuki Anyoji, Interdisciplinary Graduate School of Engineering Sciences, Kyushu University, 6-I Kasugakoen, Kasuga-city, Fukuoka, Japan, Tel +8I-92-583-7583, Email anyoji.masayuki.660@m.kyushu-u.ac.jp
\end{abstract}

Received: August 08, 2019 | Published: August 19,2019
Abbreviations: $c$, chord length $[\mathrm{mm}] ; C_{D}$, drag coefficient; $C_{L}$, lift coefficient; $D, \operatorname{drag}[\mathrm{N}] ; L$, lift $[\mathrm{N}] ; R e$, Reynolds number; $\alpha$, angle of attack [degree]

\section{Introduction}

The aerodynamic performance of low-Reynolds number airfoils in chord Reynolds numbers $(R e)$ less than $10^{5}$ is important for various engineering applications, such as micro air vehicles, unmanned air vehicles, and low-speed/high-altitude aircrafts. ${ }^{1}$ Recently, a new application for low-Reynolds-number aircraft has emerged to enable aerial exploration on Mars; this so-called Mars airplane has been considered and discussed for a several years in Japan. ${ }^{2-5}$ A Japanese research group has already developed the first prototype for the Mars airplane with a fixed wing, which performed a high-altitude flightdemonstration test in $2016 .^{6}$

In such a low-Reynolds-number range, the formation and bursting of separation bubbles occur on the wing surface. This type of physical phenomenon strongly depends on airfoil shape, Reynolds number, and angle of attack, and causes non-linear lift curves as well as influences the Reynolds number effect on aerodynamic performance. Therefore, aerodynamic predictions based on physical properties are essential for high-performance wing design of low-Reynolds number aircrafts. The behavior of separation bubbles on representative symmetric airfoils, such as NACA0012 airfoil ${ }^{8,9}$ and flat plate, ${ }^{10-12}$ has been well investigated. More practical asymmetric airfoils with aerodynamic characteristics have also been reported, including SeligDonovan (SD) 7003 airfoil $^{13}$ and Ishii airfoil. ${ }^{14}$ These two airfoils have relatively high lift-to-drag $(L / D)$ ratios below $R e=70,000$ where the low-Reynolds-number effect becomes pronounced ${ }^{15}$ and are known as high-performance airfoils at low-Reynolds numbers. In particular, Ishii airfoil is considered a likely main-wing airfoil candidate for the Japanese Mars airplane due to its high $L / D$ around the cruising Reynolds number of 23,000. Aono et al., ${ }^{16}$ compared the aerodynamic characteristics of these two airfoils at $R e=23,000$ via large-eddy simulations. The results revealed that the airfoil shape of the upper surface dominates both the formation of laminar separation bubbles and the transition to turbulence around the airfoil. Moreover, the lower surface of the airfoil shape does not significantly affect the flow structure around the airfoil because the attached flow is commonly maintained on the lower surface. Although aerodynamic characteristics and flowfields around the airfoils at the specific Reynolds numbers have been studied, knowledge is still lacking about how the Reynolds number affects aerodynamic characteristics. Since low-Reynolds number aircrafts such as the Mars airplane fly at various altitudes and speeds, it is necessary to reveal how changes in the Reynolds number impact aerodynamic performance, especially lift characteristics. This study investigates the Reynolds number effect on the lift and drag characteristics of Ishii and SD7003 airfoils. In the flight sequence assumed for the Japanese Mars airplane, a Reynolds number less than 23,000 is a transitive condition. Thus, the Reynolds number was changed from 23,000 to 60,000. Additionally, the flowfield around the airfoils were visualized by employing the smoke-wire method at $R e$ $=23,000$.

\section{Experimental setup and conditions}

\section{Test model}

The geometries of Ishii and SD7003 airfoils are presented in Figure 1 , and their features are tabulated in Table 1 . The coordinate data for the Ishii airfoil is given. ${ }^{14}$ Although the location of the maximum thickness hardly changes, the thickness of SD7003 is slightly larger than that of Ishii. Further, there is no large difference in the geometry of the upper surface; however, the difference in the lower surface shape becomes noticeable, especially around the position $x / c=$ 0.4-0.6, where the under camber of the Ishii airfoil is strong, which makes the camber of the Ishii airfoil larger than that of SD7003. Both airfoils have a small leading edge radius, which is consistent with the shape features of the high-performance low-Reynolds number airfoil proposed by Schmitz. ${ }^{17,18}$

Both test models are made of high-transmission stereolithography resins. The chord and span lengths of the test models are $80 \mathrm{~mm}$ and $180 \mathrm{~mm}$, respectively.

\section{Aerodynamic force measurement and flow visualization}

We conducted a series of experiments using an open-circuit lowspeed wind tunnel at Kyushu University. Four screens and a honeycomb 
were installed upstream of the contraction section for turbulence reduction, and the contraction ratio was $1 / 8$. The turbulence intensity at the test section center was approximately $0.3 \%$ at $5.0 \mathrm{~m} / \mathrm{s}$. Figure 2 displays the full experimental setup. The rectangular cross-section of the test section measured $180 \mathrm{~mm} \times 360 \mathrm{~mm}$, and the test section was covered on all sides with acrylic sidewalls. The test model was installed perpendicular to the ground and connected to a three-component micro-force balance system (LMC-3501-5N, NISSHOELECTRICWORKS) to perform aerodynamic force measurements. Each related load of the balance system was $5 \mathrm{~N}$ for both the lift and drag forces and $0.5 \mathrm{Nm}$ for the momentum. Since the lift and drag forces were calibrated beforehand using standard weights, the uncertain accuracy of the aerodynamic force measurements is estimated to be $0.2 \%$. Regarding the gap between the sidewall and the model tip, Rae et al. ${ }^{19}$ express that the gap should be less than $0.5 \%$ of the span length. Meanwhile, Burns et al. ${ }^{20}$ indicate that gap sizes ranging from 0.1 to $1.4 \mathrm{~mm}$ are usually acceptable and do not affect aerodynamic force measurements. Based on these results, the gap was adjusted to $0.5 \mathrm{~mm}$. Flow visualizations around the airfoils were conducted with the same test-model setup for the aerodynamic force measurements using a smoke-wire technique. Two nichrome wires with $0.1-\mathrm{mm}$ diameters coated in liquid paraffin were horizontally installed at the inlet of the test section and heated by passing an electrical current from a volt slider (S-130-10, YAMABISHI ELECTRICS) to generate smoke. A green laser with 2W output (SDL-532-2000T, Scitec Instruments Ltd.) was used as a light source. The smoke-line was then recorded using a high-speed video camera (Miro C110, Phantom).

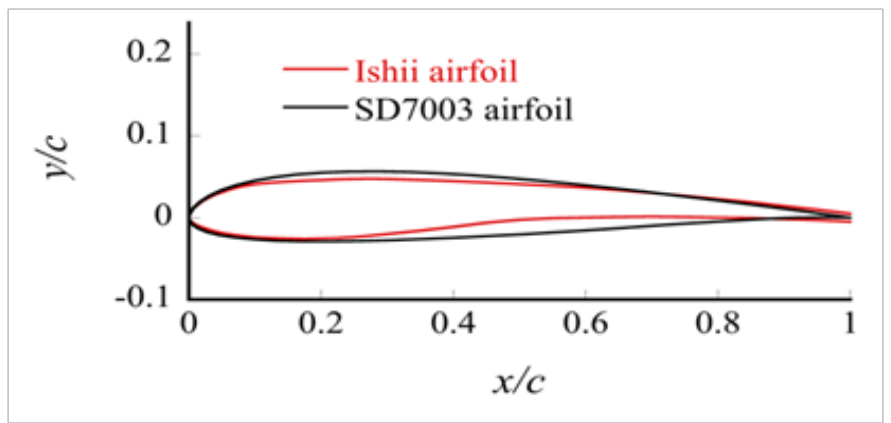

Figure I Airfoil shape (Red line: Ishii airfoil, Black line: SD7003 airfoil).

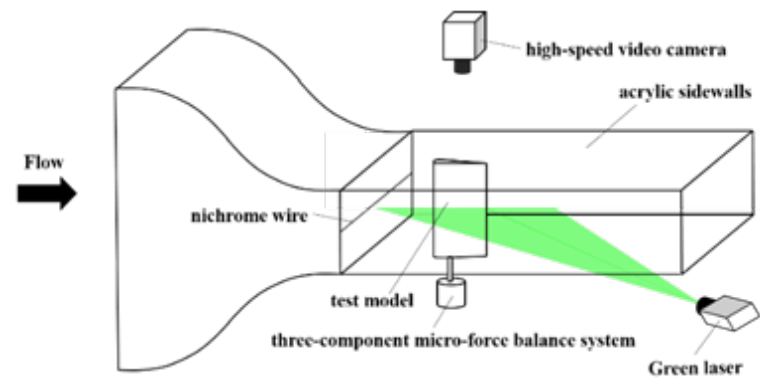

Figure 2 Experimental setup.

Table I Geometric features of airfoils

\begin{tabular}{llll}
\hline & $\begin{array}{l}\text { Maximum } \\
\text { thickness (\%) }\end{array}$ & $\begin{array}{l}\text { Location (x/c) } \\
\text { of Maximum } \\
\text { thickness }\end{array}$ & $\begin{array}{l}\text { Maximum } \\
\text { camber (\%) }\end{array}$ \\
\hline Ishii airfoil & 7.1 & 0.25 & 2.3 \\
$\begin{array}{l}\text { SD7003 } \\
\text { airfoil }\end{array}$ & 8.5 & 0.24 & 1.5 \\
\hline
\end{tabular}

\section{Experimental conditions}

The aerodynamic force measurements were performed in the chord-based Reynolds number range from 23,000 to 60,000. The angle of attack $(\alpha)$ was changed from $\alpha=-10^{\circ}$ to $15^{\circ}$ in $1^{\circ}$ increments. The flow visualization was performed only at positive angles of attack at $R e=23,000$ on the upper and lower surfaces, respectively. The frame rate of the high-speed video camera was 400 frames per second with an exposure time of $2,400 \alpha$ s. Accordingly, the image resolution of the camera was $1280 \times 1024$ pixels.

\section{Results and discussion}

\section{Aerodynamic characteristics and flow field at $R e$ $=23,000$}

Figure 3 illustrates a comparison of the lift coefficients, drag coefficients, and lift-to-drag ratios $(L / D)$ between the SD7003 and Ishii airfoil at $R e=23,000$. There is almost no difference in the lift curves from $\alpha=-2^{\circ}$ to $4^{\circ}$. The two curves share common features, such as the obvious non-linearity at $\alpha=4^{\circ}$ and maximum lift angle of attack around $\alpha=8^{\circ}$. However, the difference in lift characteristics at both negative and high angles of attack is observed. In particular, the maximum lift coefficient $\left(C_{L \max }\right)$ is 0.75 for SD7003, while that of Ishii airfoil is 0.90. While drag coefficients for the SD7003 airfoil at negative angles of attack are smaller, those of Ishii airfoils are smaller at positive angles of attack. These results mean that the $L / D$ of the Ishii airfoil is much larger than that of SD7003 at positive angles of attack, and the maximum $L / D\left(L / D_{\max }\right)$ of the Ishii airfoil is approximately 1.4 times that of SD7003. Compared with the CFD results by Aono et al. ${ }^{16}$ our results are reasonable. Therefore, it can be concluded that the lift and drag characteristics of the Ishii airfoil at $R e=23,000$ are superior to those of SD7003.

Figures 4 \& 5 exhibit the visualization results of the SD7003 and Ishii airfoils at $R e=23,000$, respectively. Meanwhile, the separation and reattachment points on the upper surface based on the visualization results are plotted in Figure 6. In the flowfields of the SD7003 airfoil pictured in Figure 4, the trailing edge separation occurs at low angles of attack, and the separation point gradually moves upstream as the angle of attack increases. The separated shear layer rolls up and starts to form a span-wise vortex in the vicinity of the trailing edge at $\alpha=3^{\circ}$, which is associated with a laminar to turbulent transition of the separated shear layer. The separated shear layer reattaches to the upper surface, and a separation bubble forms between separation and reattachment points at $\alpha=4^{\circ}$. This separation bubble gently moves upstream as the angle of attack increases up to $\alpha=8^{\circ}$. Since the forward flow due to the reattachment on the upper surface could not be observed at $\alpha=9^{\circ}$, we judged that a leading edge separation occurs. The flow attaches to the lower surface at all angles of attack. As depicted in Figures 5 \& 6, the flowfield on the upper surface of the Ishii airfoil is almost the same as that of SD7003 shown in Figure 4. Despite these similar flowfields, there is a clear difference in aerodynamic performance, especially at high angles of attack exceeding $\alpha=5^{\circ}$. This discrepancy can be attributed to the difference in pressure distribution on the lower surface, which is caused by the different airfoil shape of the lower surface. ${ }^{16}$

\section{Reynolds number dependence on aerodynamic performance}

The aerodynamic performance of the SD7003 and Ishii airfoils from $R e=23,000$ to $R e=60,000$ are presented in Figures $7 \& 8$, respectively. Concerning the SD7003 airfoil in Figure7, the angle of attack at which the non-linear lift increase becomes smaller as the 
Reynolds number increases, and the $C_{\text {Lmax }}$ increases. The drag curve exhibits a significant Reynolds number dependence, especially at positive angles of attack.

On the other hand, the lift and drag curves of the Ishii airfoil in Figure 8 exhibit a smaller Reynolds number effect than those of SD7003. There is minimal Reynolds number dependence on the lift curve, while a slight difference at high angles of attack above the maximum lift angles of attack is found. In terms of design for the flight control system, an airfoil with low-Reynolds-number dependence under various flight altitudes and cruising speeds is desirable. Thus, a lift curve without Reynolds number dependence is an excellent feature scarcely reported in the past studies for low-Reynolds-number airfoils. Schmitz ${ }^{17,18}$ proposed to fix the separation point by implementing a sharp leading edge that can reduce the Reynolds number dependence on the lift curve. In fact, the experimental results reported by Anyoji et al., ${ }^{10}$ reveal that a flat plate with a blunt leading edge has a lift curve with low-Reynolds-number dependence below $R e=40,000$. However, when the separation point is fixed at the leading edge, as in the case of a flat plate, the pressure drag increases. Therefore, the total drag increases and a high $L / D$ ratio cannot be obtained. For the Ishii airfoil with a rounded leading edge, as shown in Figure 6, e the separation point stays upstream of the maximum thickness point $(x / c=0.25)$ and does not move significantly compared to that of the SD7003 airfoil when the separation bubble is formed even if the angle of attack varies. We deduce that this may reduce the Reynolds number effect on the lift curve as a function similar to that of the flat plate. It is considered that the slight difference in the upper surface shape near the leading edge between the SD7003 and Ishii airfoils is highly sensitive to the Reynolds number dependence on aerodynamic performance. The drag coefficients have almost no asymmetry at positive and negative angles of attack and gradually decrease with increasing Reynolds numbers. The $L / D_{\max }$ of the Ishii airfoil is also higher than that of SD7003 at all Reynolds numbers. Hence, it can be interpreted that the Ishii airfoil with low-Reynolds-number dependence is not only easy to handle, but also has high aerodynamic performance.

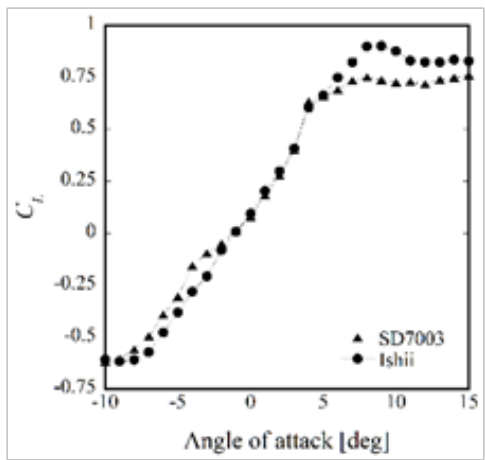

(a)Lift

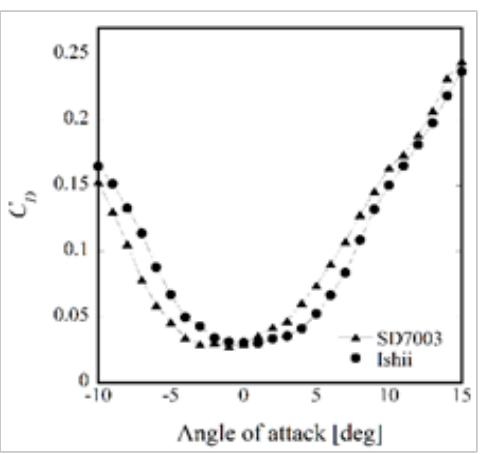

(b) Drag

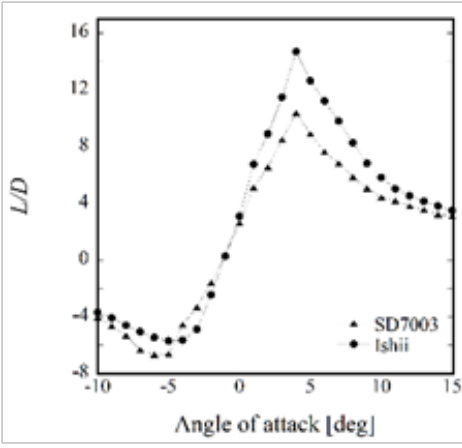

(c) Lift/Drag

Figure 3 Comparison of aerodynamic performance at $R e=23,000$

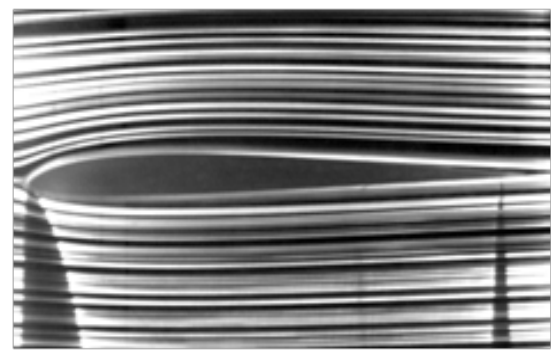

(a) $\alpha=0$ deg

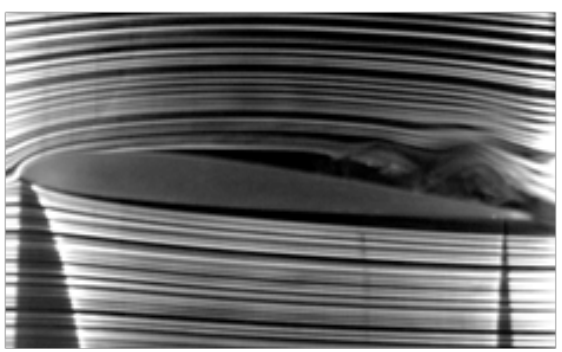

(d) $\alpha=6$ deg

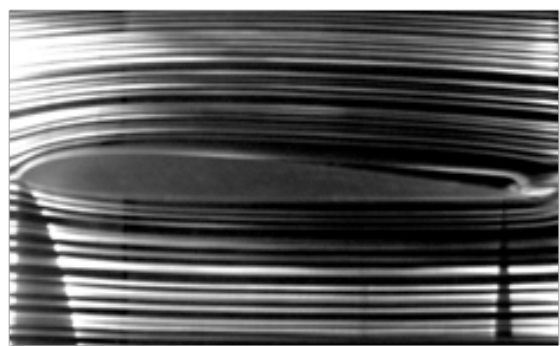

(b) $\alpha=3$ deg

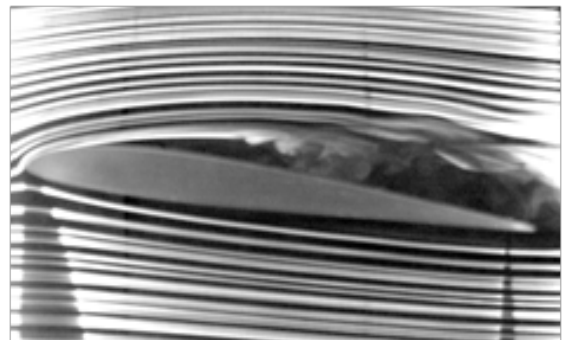

(e) $\alpha=8 \mathrm{deg}$

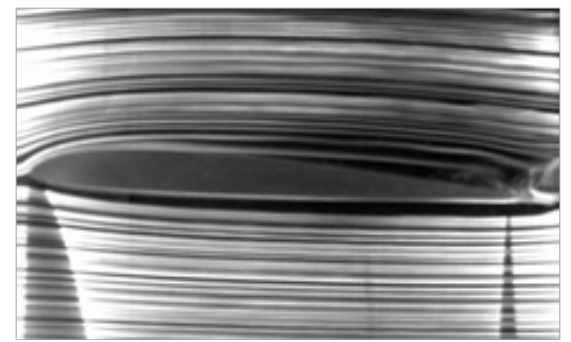

(c) $\alpha=4$ deg

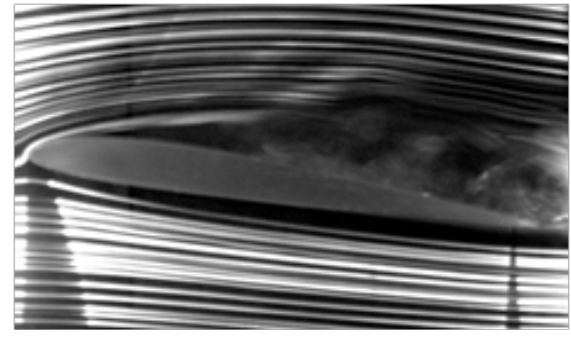

(f) $\alpha=9$ deg

Figure 4 Flowfield around SD7003 airfoil $(R e=23,000)$. 


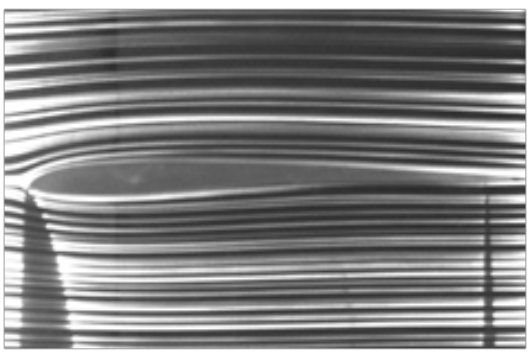

(a) $\alpha=0$ deg

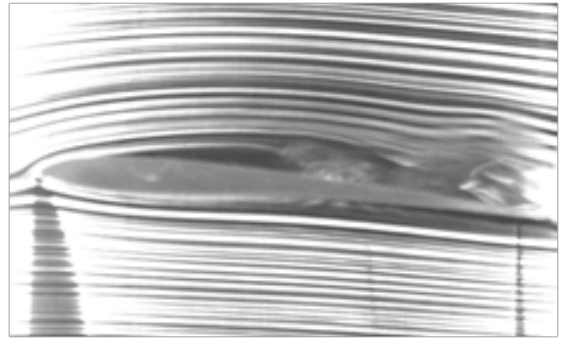

(d) $\alpha=5 \mathrm{deg}$

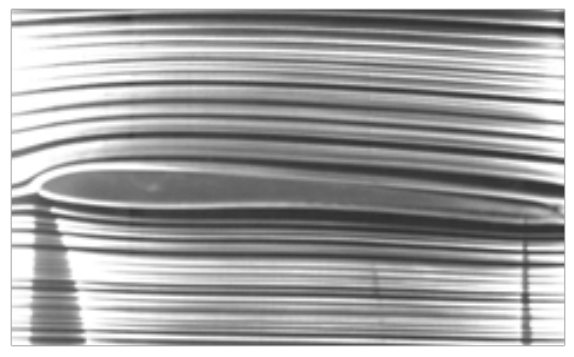

(b) $\alpha=3 \mathrm{deg}$

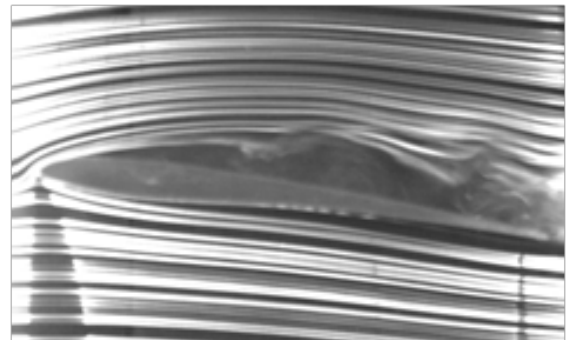

(e) $\alpha=8 \mathrm{deg}$

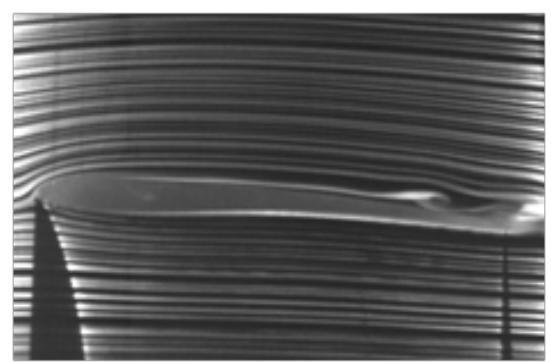

(c) $\alpha=4$ deg

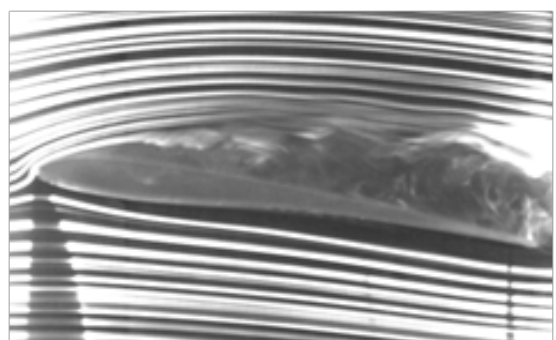

(f) $\alpha=9 \mathrm{deg}$

Figure 5 Flowfield around Ishii airfoil $(R e=23,000)$.

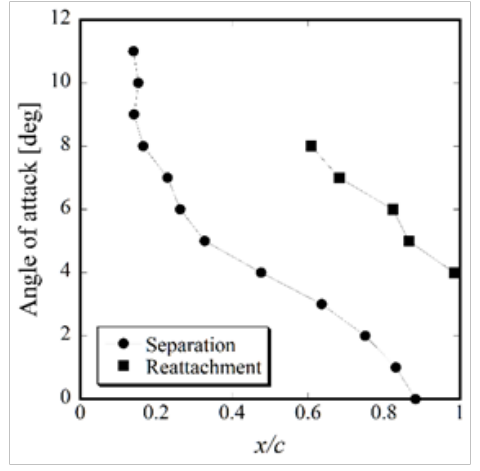

(a) SD7003 airfoil

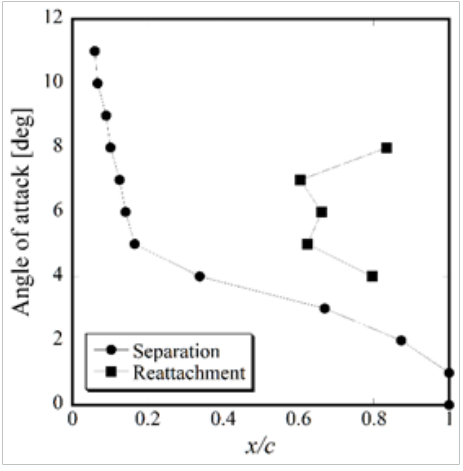

(b) Ishii Airfoil

Figure 6 Location of separation and reattachment points.

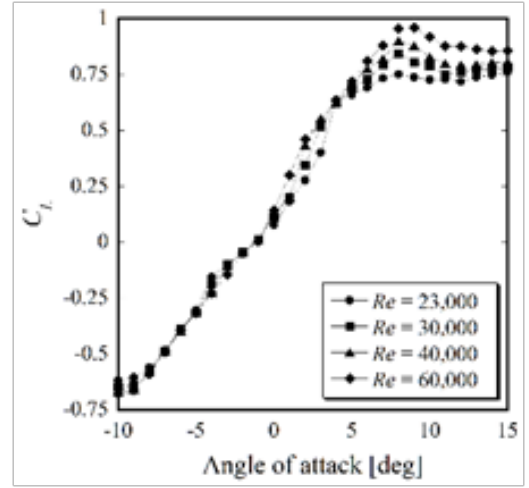

(a)Lift

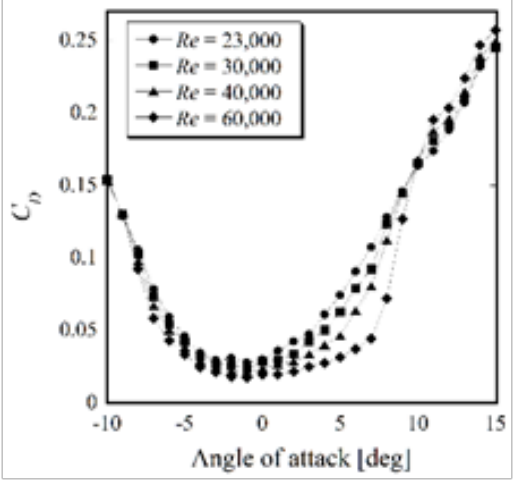

(b) Drag

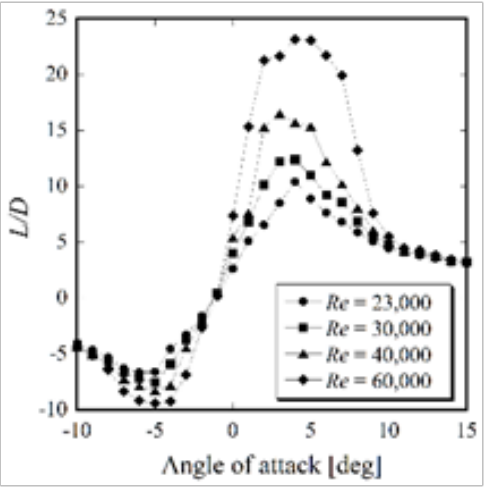

(c) Lift/Drag

Figure 7 Reynolds number dependence on aerodynamic characteristics of sd7003 airfoil. 


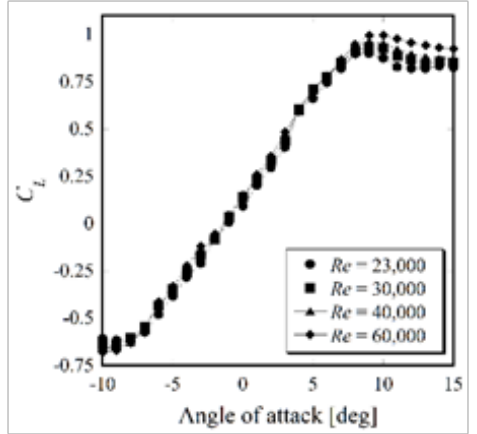

(a)Lift

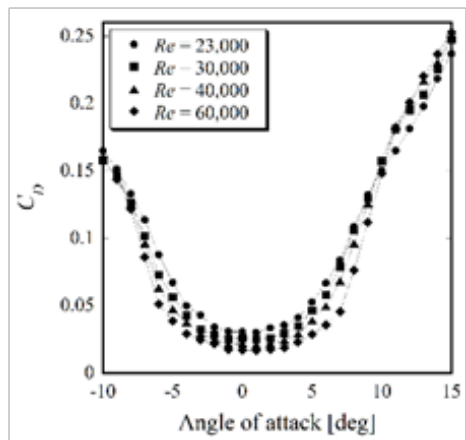

(b) Drag

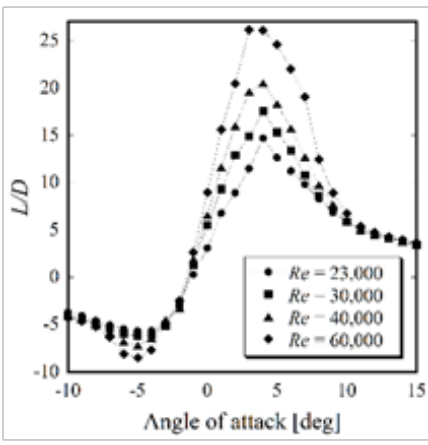

(c) Lift/Drag

Figure 8 Reynolds number dependence on aerodynamic characteristics of Ishii airfoil.

\section{Conclusion}

In this study, we performed aerodynamic measurements and flow visualizations at low-Reynolds numbers $(R e=23,000-60,000)$ to investigate how the Reynolds number influences the lift and drag characteristics of two high-performance low-Reynolds-number airfoils, Ishii and SD7003. The Ishii airfoil not only has higher aerodynamic performance than SD7003 at all Reynolds numbers, but also has low-Reynolds-number dependence on the lift curve. The visualization results at $R e=23,000$ indicate that the separation point stays upstream of the maximum thickness point and does not drastically move when the separation bubble is formed even if the angle of attack varies. That is, the Ishii airfoil with a rounded leading edge radius can fix near the leading edge in the same way as a flat plate with a blunt leading edge. Thus, in the range of $R e=23,000$ 60,000 , Ishii airfoil is a high-performance airfoil that is easy to handle for a Mars airplane or other low-Reynolds-number aircrafts.

\section{Acknowledgments}

We would like to express our sincere thanks to Yuki Ohkubo and Mitsuru Nakauchi, who graduated from Kyushu University, for their contributions to this study.

\section{Conflicts of interest}

The author declares there is no conflicts of interest.

\section{References}

1. Mueller TJ, De Laurier JD. Aerodynamics of small vehicles. Ann Rev Fluid Mech. 2003;35(1):89-111.

2. Nagai H, Oyama A. Mission scenario of Mars exploration by airplane Proceedings of the 2013 Asia-Pacific International Symposium on Aerospace Technology. 2013.

3. Nagai H, Oyama A. Development of Mars exploration aerial vehicle in Japan. Proceedings of 30th International Symposium on Space Technology and Science. 2015.

4. Nagai H. Aerodynamic challenge to realize Mars airplane. Proceedings of 30th International Symposium on Space Technology and Science. 2015.

5. Oyama A, Yonemoto K, Takeuchi S, et al. Multiobjective design exploration of a Mars Exploration Airplane. Proceedings of 55th Space Sciences and Technology Conference. 2011.
6. Anyoji M, Okamoto M, Fujita K, et al. Evaluation of aerodynamic performance of Mars airplane in scientific balloon experiment. Fluid Mech Res Int J. 2017;1(3):0012.

7. Mueller TJ, Batill SM. Experimental studies of separation on a twodimensional airfoil at low Reynolds number. AIAA J. 1982;20(4):457-463.

8. Ohtake T, Nakae Y, Motohashi T. Nonlinearity of the aerodynamic characteristics of NACA0012 aerofoil at low reynolds numbers. J Japan Soc Aeronautical and Space Sciences. 2007;55(644):439-445.

9. Winslow J, Otsuka H, Govindarajan B, et al. Basic understanding of airofil characteristics at low reynolds numbers (104-105). J Aircraft. 2018;55(3):1050-1061.

10. Anyoji M, Numata D, Nagai $\mathrm{H}$, et al. Effects of mach number and specific heat ratio on low-reynolds-number airfoil flows. AIAA J. 2014;53(6):1640 1654 .

11. Lee D, Kawai S, Nonomura T, et al. Mechanisms of surface pressure distribution within a laminar separation bubble at different Reynolds numbers. Phys Fluids. 2015;27(2):023602.

12. Okamoto M, Azuma A. Aerodynamic characteristics at low reynolds numbers for wings of various planforms. AIAA J. 2012;49 (6):1135-1150.

13. Selig MS, James J Guglielmo, Andy P Broeren, et al. Summary of Lowspeed Airfoil Data. Soartech Aero Publications. 1995.

14. Anyoji M, Nonomura $\mathrm{T}$, Aono $\mathrm{H}$, et al. Computational and experimental analysis of a high-performance airfoil under low-Reynolds number flow condition. J Aircraft. 2014;51(6):1864-1872.

15. Drela M. Transonic low-reynolds number airfoils. $J$ Aircraft. 2012;29(6):1106-1113.

16. Aono H, Nonomura T, Anyoji M, et al. A numerical study of the effects of airfoil shape on low reynolds number aerodynamics. Proceedings of the 8th International Conference on Engineering Computational Technology. 2012.

17. Schmitz FW. Aerodynamics of the model airplane part 1. Redstone Scientific Information Center Rept. 1967;1-203.

18. Schmitz FW. The aerodynamics of small reynolds number. 1980;1-51.

19. Rae Jr WH, Pope A. Low-speed wind tunnel testing. 2nd edn. John Wiley \& Sons Inc, New York; 1984

20. Burns TF, Mueller TJ. Experimental studies of the Eppler 61 airfoil at low reynolds numbers. AIAA. 2012. 